\title{
Clinical and prognostic significance of HIF- 1a overexpression in oral squamous cell carcinoma: a meta-analysis
}

\author{
Jianhua Zhou ${ }^{1,2,3}$, Shengyun Huang ${ }^{2}$, Lili Wang ${ }^{4}$, Xiao Yuan ${ }^{3}$, Quanjiang Dong ${ }^{4}$, Dongsheng Zhang ${ }^{1,2^{*}}$ \\ and Xuxia Wang ${ }^{1 *}$
}

\begin{abstract}
Background: Recent studies have indicated an association between hypoxia inducible factor-1 alpha (HIF-1a) expression and poor prognosis in patients with oral squamous cell carcinoma (OSCC); however, definitive evidence of this association is yet to be obtained. We performed a meta-analysis to evaluate the association of HIF-1a expression with clinicopathological characteristics and overall survival (OS) of patients with OSCC.

Methods: A literature search for relevant studies published in English language as of February 05, 2016, was performed on PubMed, Web of Science, and EMBASE databases. Eighteen studies with a combined study population of 1474 patients with OSCC are included in the meta-analysis. Odds ratio (OR) or hazard ratio (HR) with 95\% confidence interval (Cl) was calculated using random-effects model or fixed-effects model.

Results: HIF-1a overexpression was significantly associated with larger tumor size $(\mathrm{OR}=2.28,95 \% \mathrm{Cl}=1.49-3.50$, $P=0.017)$, advanced TNM stage $(\mathrm{OR}=2.29,95 \% \mathrm{Cl}=1.50-3.49, P=0.158)$, and lymph node metastasis $(\mathrm{OR}=2.05$, $95 \% \mathrm{Cl}=1.19-3.53, P<0.001)$, but not with poor differentiation $(\mathrm{OR}=1.21,95 \% \mathrm{Cl}=0.55-2.64, P=0.024)$. These results demonstrated an association between HIF-1a expression and biological behavior of OSCC. On pooled analyses, high expression of HIF-1a was associated with worse OS ( $\mathrm{HR}=1.70,95 \% \mathrm{Cl}=1.10-2.61, P<0.001)$. On subgroup analyses, overexpression of HIF-1a was significantly associated with poor prognosis in Asian population $(\mathrm{HR}=2.33,95 \% \mathrm{Cl}=1.72-3.15, P=0.862)$.
\end{abstract}

Conclusions: Our findings demonstrate an association of HIF-1a overexpression with tumor size, tumor stage, lymph node metastasis, and overall survival. HIF-1a could be an independent prognostic marker in patients with OSCC.

Keywords: Oral squamous cell carcinoma, Prognosis, Hypoxia inducible factor-1a, Meta-analysis

\section{Background}

Oral squamous cell carcinoma shows a high propensity for invasive growth and cervical lymph node metastasis [1]. Every year, an estimated 263,000 new cases of oral squamous cell carcinoma (OSCC) are reported worldwide [2]. Five-year survival rates of patients with OSCC have remained in the vicinity of $50 \%$ over the last few decades [3, 4].

Solid malignant tumors tend to show rapid proliferation and growth in a hypoxic microenvironment [5]. Hypoxia

\footnotetext{
* Correspondence: ds63zhang@sdu.edu.cn; wangxuxia2016@sohu.com ${ }^{1}$ Department of Oral and Maxillofacial Surgery, School of Stomatology, Shandong University, Jinan, Shandong 250012, China

Full list of author information is available at the end of the article
}

inducible factor-1 (HIF-1) is an important regulator of cellular response to hypoxia. It is a heterodimer that comprises of HIF- $1 \alpha$ and HIF- $1 \beta$ subunits [5-7], the former being its functional subunit [8]. High expression levels of HIF-1 $\alpha$, a marker of tumor hypoxia, have been reported in patients with OSCC [9]. Overexpression of HIF-1 $\alpha$ has recently been linked with unfavorable prognosis in several types of malignant tumors [10, 11]. However, definitive evidence of this association is yet to be obtained.

Though a previous meta-analysis revealed an association between HIF- $1 \alpha$ expression and poor overall survival in patients with OSCC, the analysis was not comprehensive [12]. The main prognostic factors for OSCC include tumor size, lymph node status, tumor 
stage, and differentiation. We performed a literature review to evaluate the association of HIF- $1 \alpha$ expression with clinicopathological characteristics and overall survival in patients with OSCC.

\section{Methods}

\section{Search strategy}

Full-text original research articles relating to expression of HIF- $1 \alpha$ in patients with OSCC were identified on a search of PubMed, Web of Science, and EMBASE databases on February 05, 2016. The following keywords were used: "hypoxia inducible factor $1 \alpha$," "HIF $1 \alpha$," "oral squamous cell carcinoma," "OSCC," "mouth neoplasm," "oral cancer," "oral carcinoma," or "oral tumor" with all possible combinations.

The inclusion criteria were as follows: (1) Language of publication: English; (2) studies that investigated the correlation between HIF- $1 \alpha$ and prognosis in patients with a histopathological diagnosis of squamous cell carcinoma; (3) HIF- $1 \alpha$ protein expression determined by immunohistochemical examination of paraffin-embedded surgical specimens; and (4) adequate data for estimation of hazard ratio and overall survival reported.

Conference abstracts, reviews, letters, case reports, unpublished studies, duplicate publications, and experimental studies were excluded from the analysis.

\section{Data extraction}

Two researchers independently reviewed the eligible studies and performed data extraction using a standard format. Data pertaining to the following variables were extracted: name of first author, year of publication, country, sex distribution, sample size, definition of HIF$1 \alpha$ positive, clinicopathological features, and overall survival analysis. Any disagreement on the eligibility criteria was resolved by consensus among the authors.

\section{Methodological assessment}

The Newcastle-Ottawa quality assessment scale (NOS) was used for methodological assessment of the included studies [13]. The maximum score was 9; studies with a total score of $\geq 6$ points were deemed to be of a high quality. Two researchers assessed the scores independently; any disagreements in this respect were resolved by consensus.

\section{Statistical analyses}

Statistical analyses were performed using Stata (version 11.0; Stata Corporation, College Station, Texas, USA). Kaplan-Meier curves were plotted using Engauge Digitizer version 4.1 (free software downloaded from http://sourceforge.net). Hazard ratio at $95 \%$ confidence interval was used to assess the relationship between HIF- $1 \alpha$ and overall survival. An HR $>1$ correlated with poor prognosis. HRs were either estimated directly from the reported data using methods described by Parmar et al. [14] or were derived from the Kaplan-Meier curve. Odds ratio at 95\% CI were calculated to evaluate the association of HIF- $1 \alpha$ expression with clinicopathological features.

Heterogeneity of the included studies was checked by chi-square-based Q statistical test. A value of $I^{2}<50 \%$ or $P$ value $>0.1$ was considered to be indicative of no significant heterogeneity, and a fixed-effects model was used for analysis. Otherwise, the random-effects model was used.

Sensitivity analysis was performed to evaluate the robustness of the individual studies. Begg's funnel plot and Egger's regression test were used to evaluate the effect of potential publication bias on the results of this analysis [15]. All $P$ values were two-sided; $P<0.05$ was considered as statistically significant.

\section{Results}

\section{Study characteristics}

As shown in Fig. 1, a total of 224 studies were retrieved on initial literature search. After scanning the titles, abstracts, and full texts, 18 studies [5, 6, 16-30] were finally included in the meta-analysis. All studies were retrospective analytic studies and were published between 2005 and 2015. Out of the 18 studies, 15 had assessed the relationship between HIF- $1 \alpha$ expression and clinicopathological features, and 14 studies had reported survival data directly or indirectly. The sample sizes ranged from 25 to 233 cases (mean sample size, 82). The combined patient population was 1474. These included 561 patients with well- or moderately differentiated tumors, and 182 patients with poorly differentiated tumors. A total of 159 patients were categorized as clinical stage I/II disease and 264 as clinical stage III/IV disease; 539 patients were graded as T1/T2 and 531 patients as T3/T4. A total of 610 patients had

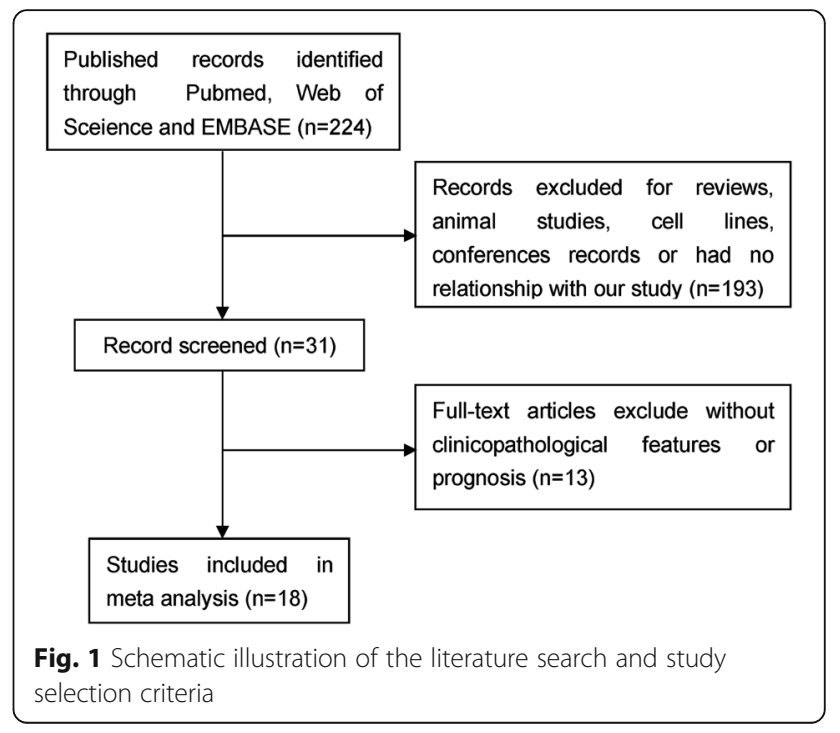


lymph node involvement, while no lymph node involvement was observed in 605 patients. These studies were completed in six countries (Brazil, Korea, China, Japan, Germany, and Australia).

Although the expression of HIF- $1 \alpha$ was determined on immunohistochemistry (IHC), the procedure varied between different studies. Table 1 shows the main characteristics and quality of these 18 included studies.

\section{Association of HIF-1a expression with clinicopathological characteristics}

Seven studies $[8,16-21]$ had reported on the association of HIF- $1 \alpha$ expression with tumor histology. High HIF- $1 \alpha$ expression did not show any significant association with poor histological differentiation $(\mathrm{OR}=1.21,95 \% \mathrm{CI}=$ $0.55-2.64, I^{2}=58.8 \%, P=0.024$; random-effects model) (Fig. 2). Ten studies [6, 8, 16-23] had assessed the association between HIF- $1 \alpha$ expression and tumor size (T3/ $\mathrm{T} 4$ vs. T1/T2). One study was excluded from the analysis owing to inconsistent cut-off values for tumor size (T3/T2 vs. tumor in situ) [24]. Owing to significant heterogeneity among the included studies, a random-effects model was applied in this meta-analysis. Pooled OR was 2.28 (95\% CI $=1.49-3.50, I^{2}=55.2 \%, P=0.017$; randomeffects model) (Fig. 3), which suggested an association between HIF-1 $\alpha$ expression and tumor size. In six studies $[6,19-21,25,26]$, patients with stage III/IV OSCC had higher levels of HIF- $1 \alpha$ expression as compared to that in patients with stage I/II tumors. The combined OR was significant $\left(\mathrm{OR}=2.29,95 \% \mathrm{CI}=1.50-3.49, I^{2}=\right.$ $37.3 \%, P=0.158$; fixed-effects model) with no significant heterogeneity (Fig. 4).

A significant association between HIF- $1 \alpha$ expression and lymph node status was reported in 13 studies $[6,8$, $16-25,28]\left(\mathrm{OR}=2.05,95 \% \mathrm{CI}=1.19-3.53, I^{2}=73 \%, P\right.$ $<0.001$; random-effects model); significant heterogeneity was observed among these studies (Fig. 5).

\section{Overall survival correlated with HIF-1a overexpression}

A total of fourteen studies (combined $N=1152$ ) had evaluated the association of HIF- $1 \alpha$ expression with overall survival. One study, for which the Kaplan-Meier curve or the original data was not available, was excluded from the meta-analysis of OS [23]. A randomeffects model was performed for the calculation of HRs owing to significant heterogeneity among these studies $\left(X^{2}=46.26, P<0.0001, I^{2}=71.9 \%\right)$.

The pooled HR for the HIF-1 $\alpha(+)$ vs. HIF- $1 \alpha(-)$ group was $1.70(95 \% \mathrm{CI}=1.10-2.61)$ (Fig. 6). On subgroup analysis, high HIF-1 $\alpha$ expression significantly correlated with poorer prognosis in Asian patients with OSCC $(\mathrm{HR}=2.33,95 \% \mathrm{CI}=1.72-3.15)$; there was no significant heterogeneity in this respect $\left(I^{2}=0.0 \%, P=0.862\right)$ (Fig. 6).

Table 1 Main characteristics and quality of the studies included in the meta-analysis

\begin{tabular}{|c|c|c|c|c|c|c|c|c|c|c|c|}
\hline \multirow[t]{2}{*}{ First author } & \multirow[t]{2}{*}{ Year } & \multirow[t]{2}{*}{ Country } & \multirow{2}{*}{$\begin{array}{l}\text { Gender } \\
\text { (male/ } \\
\text { female) }\end{array}$} & \multirow[t]{2}{*}{ Number } & \multirow{2}{*}{$\begin{array}{l}\text { Criteria used for } \\
\text { high HIF-1a } \\
\text { expression }\end{array}$} & \multirow{2}{*}{$\begin{array}{l}\text { Clinical } \\
\text { features }\end{array}$} & \multirow{2}{*}{$\begin{array}{l}\text { OS } \\
\text { analysis }\end{array}$} & \multicolumn{4}{|c|}{ Quality evaluation } \\
\hline & & & & & & & & Selection & Comparability & Outcome & Total points \\
\hline Lin & 2008 & China, Taiwan & $54 / 3$ & 57 & $>60 \%$ & NR & Reported & 3 & 0 & 2 & 5 \\
\hline Liang & 2011 & China & $49 / 40$ & 89 & $>25 \%$ & T/LN/D & Reported & 3 & 1 & 3 & 7 \\
\hline Huang & 2012 & China & $46 / 34$ & 80 & $>4^{a}$ & LN & Reported & 2 & 1 & 3 & 6 \\
\hline Han & 2012 & Korea & $20 / 13$ & 33 & $>10 \%$ & $N R$ & Reported & 4 & 1 & 2 & 7 \\
\hline Zheng & 2013 & China & $66 / 54$ & 120 & $>5 \%$ & T/LN/D & Reported & 4 & 1 & 2 & 7 \\
\hline Hwa & 2015 & Korea & $17 / 8$ & 25 & $>50 \%$ & $N R$ & Reported & 3 & 1 & 2 & 6 \\
\hline Zhu & 2010 & China & $52 / 45$ & 97 & Positive staining & T/LN/D & Reported & 3 & 1 & 3 & 7 \\
\hline Kang & 2013 & China & $28 / 21$ & 49 & $>10 \%$ & T/LN & Reported & 4 & 1 & 3 & 8 \\
\hline Hong & 2013 & Australia & $186 / 47$ & 233 & $>10 \%$ & T/LN/D & Reported & 4 & 1 & 2 & 7 \\
\hline Eckert & 2010 & Germany & $60 / 20$ & 80 & $>6^{\mathrm{a}}$ & T/LN/D/TNM & Reported & 3 & 1 & 2 & 6 \\
\hline Fillies & 2005 & Germany & $71 / 14$ & 85 & $>5 \%$ & $N R$ & Reported & 2 & 0 & 2 & 4 \\
\hline Santos & 2012 & Brazil & $56 / 10$ & 66 & $>6^{\mathrm{a}}$ & T/LN/D/TNM & Reported & 4 & 0 & 3 & 7 \\
\hline Mendes & 2014 & Brazil & $48 / 8$ & 56 & $>3^{\mathrm{a}}$ & T/LN/D/TNM & Reported & 3 & 0 & 2 & 5 \\
\hline Eckert & 2011 & Germany & $60 / 22$ & 82 & $>6^{\mathrm{a}}$ & T/LN/D/TNM & Reported & 2 & 1 & 3 & 6 \\
\hline Liang & 2008 & China & $40 / 25$ & 65 & $>10 \%$ & LN/TNM & $N R$ & 3 & 1 & 2 & 6 \\
\hline Naruse & 2011 & Japan & $72 / 48$ & 120 & $>4^{\mathrm{a}}$ & T/LN & NR & 3 & 0 & 2 & 5 \\
\hline Zhang & 2014 & China & $52 / 28$ & 80 & $>4^{\mathrm{a}}$ & T/LN/D & $N R$ & 3 & 1 & 1 & 5 \\
\hline Vasconcelos & 2015 & Brazil & $40 / 17$ & 57 & $>10 \%$ & TNM & NR & 2 & 1 & 1 & 4 \\
\hline
\end{tabular}

NR not reported, $T$ tumor size, $L N$ lymph node status, TNM TNM stage, $D$ differentiation

${ }^{a}$ The final score for samples was calculated based on a combination of percentage of stained cells and staining intensity 


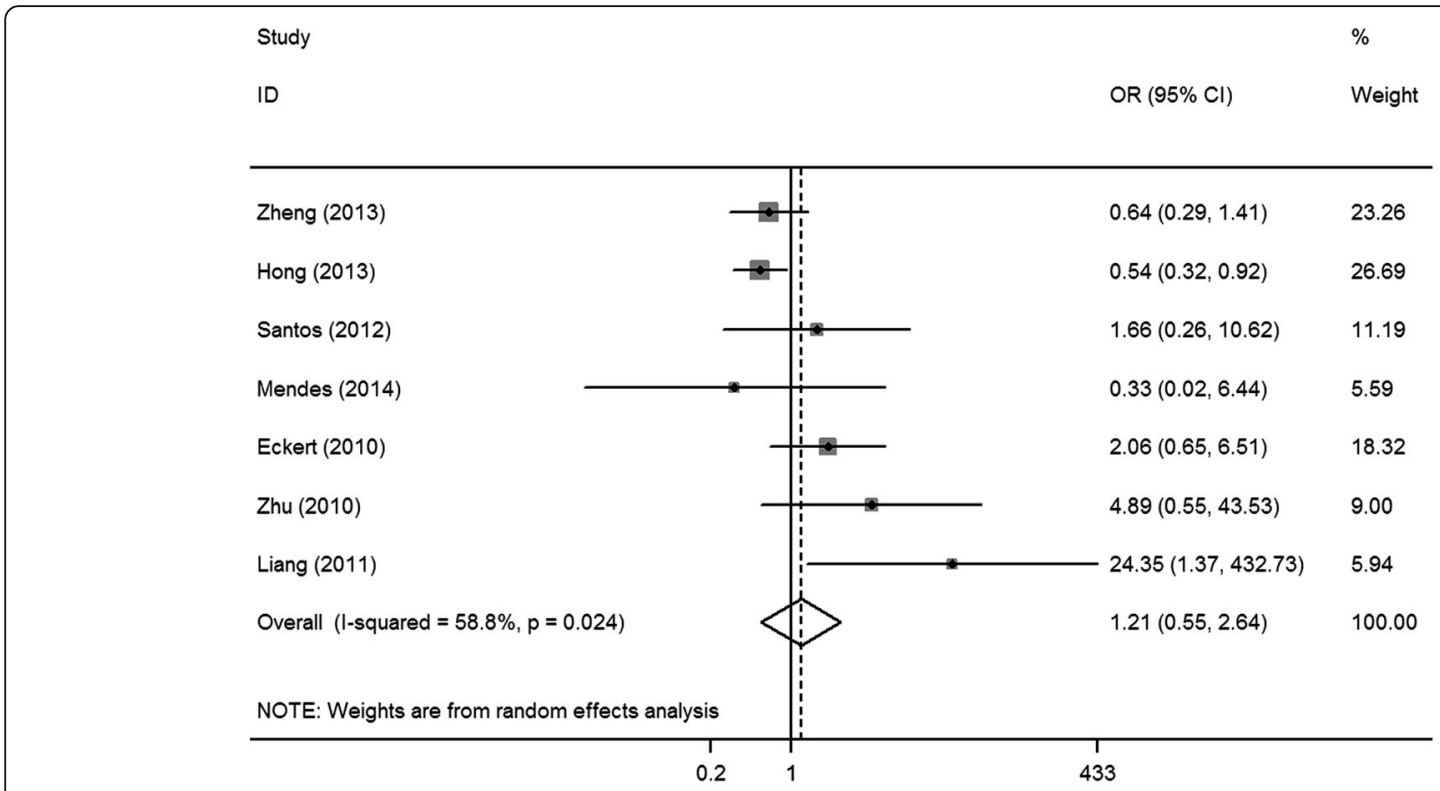

Fig. 2 Forest plot of the association between HIF-1a expression and histological differentiation of OSCC

\section{Sensitivity analysis and publication bias}

Sensitivity analysis was performed to evaluate the robustness of the analysis. Pooled HR was not significantly influenced by any single study, as indicated by analysis performed after a sequential omission of one study at a time (data not shown). Both Begg's (Fig. 7) and Egger's (data not shown) tests indicated a lack of significant publication bias $(P>0.05)$.

\section{Discussion}

Oral squamous cell carcinoma is a fatal disease; the typically poor prognosis is attributable to its invasive growth. Surgical resection is the mainstay of treatment. Nonetheless, survival rates of patients with OSCC have not shown improvement over the last few decades. More reliable therapeutic biomarkers are urgently needed for the treatment of OSCC. The results of our meta-analysis

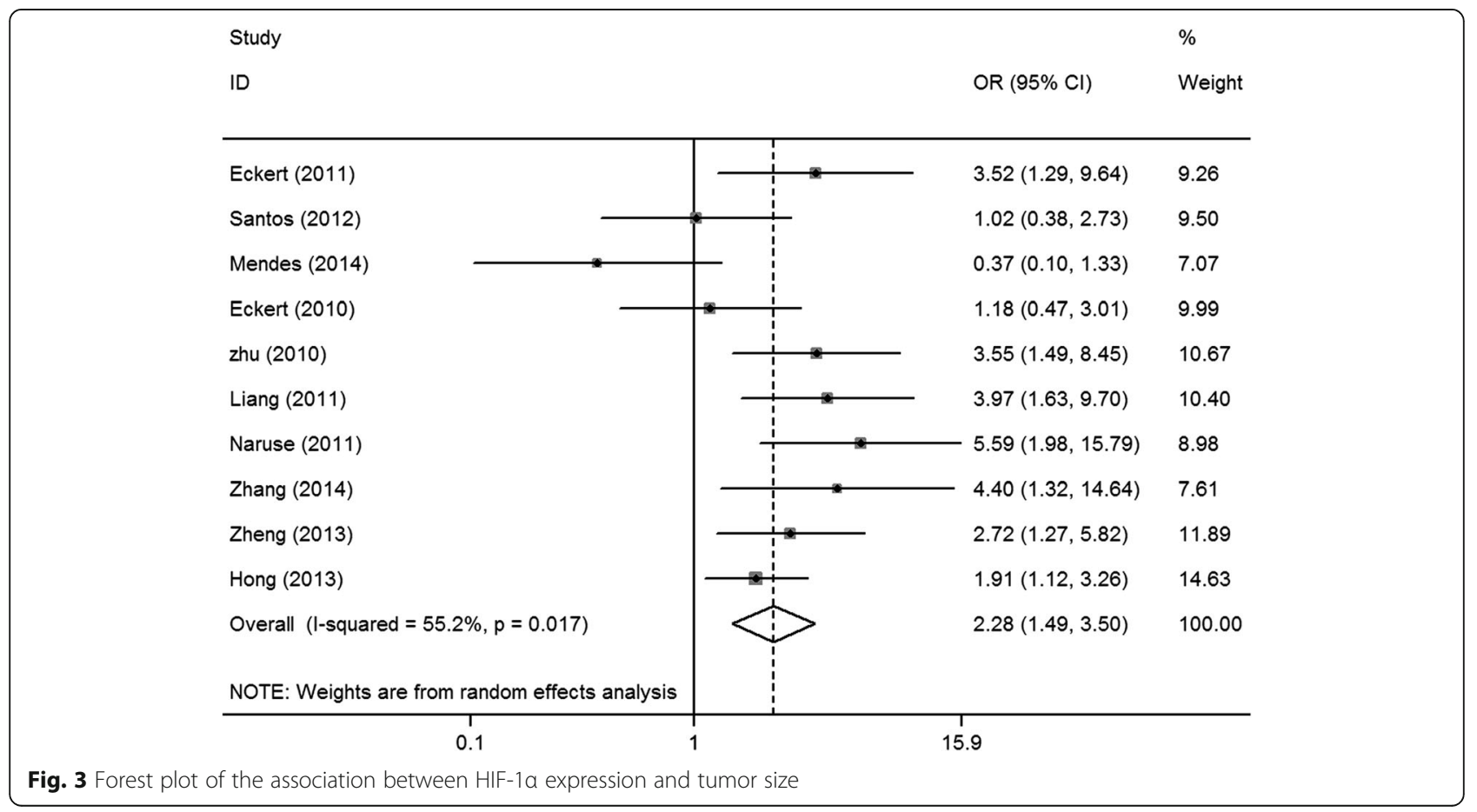




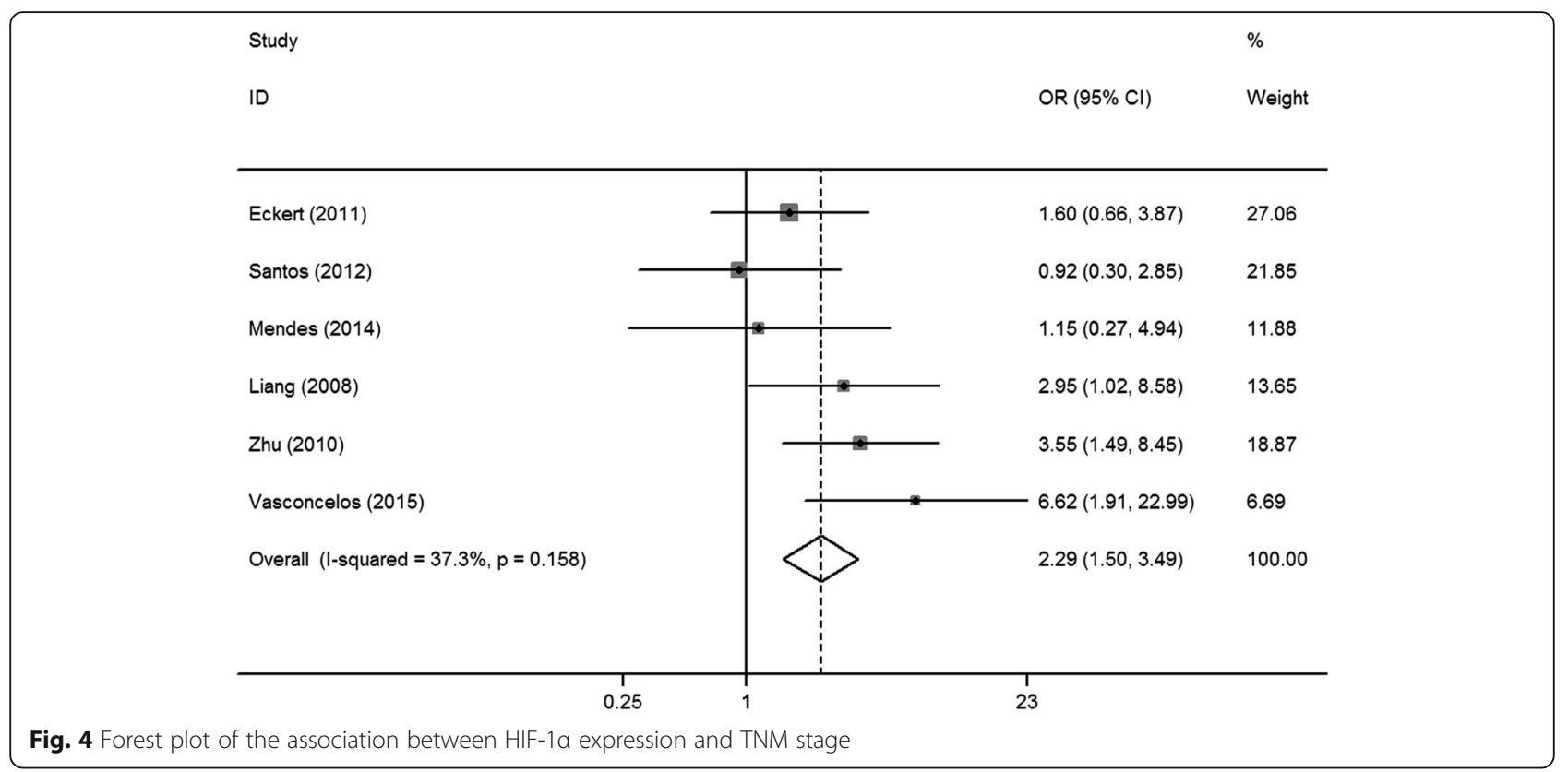

showed an association of HIF- $1 \alpha$ expression levels with clinicopathological characteristics and overall survival of these patients.

HIF- $1 \alpha$ degradation is inhibited under hypoxic conditions as well as under some conditions also under normoxic conditions [31]. HIF- $1 \alpha$ activates the transcription of downstream target genes which regulate many biological processes, including angiogenesis, cell proliferation, glucose metabolism, $\mathrm{pH}$ regulation, and migration [12,
32]. Overexpression of HIF- $1 \alpha$ has been shown to be associated with tumor cell growth in patients with cervical, endometrial, gastric, colorectal, pancreatic, ovarian, breast, and head/neck carcinomas [33-37]. However, a consensus on this association is yet to be attained.

Zhu et al. reported a significant association of HIF- $1 \alpha$ overexpression with tumor stage, histological differentiation, lymph node status, and poor prognosis [21]. In contrast, Fillies et al. reported significantly lower OS in

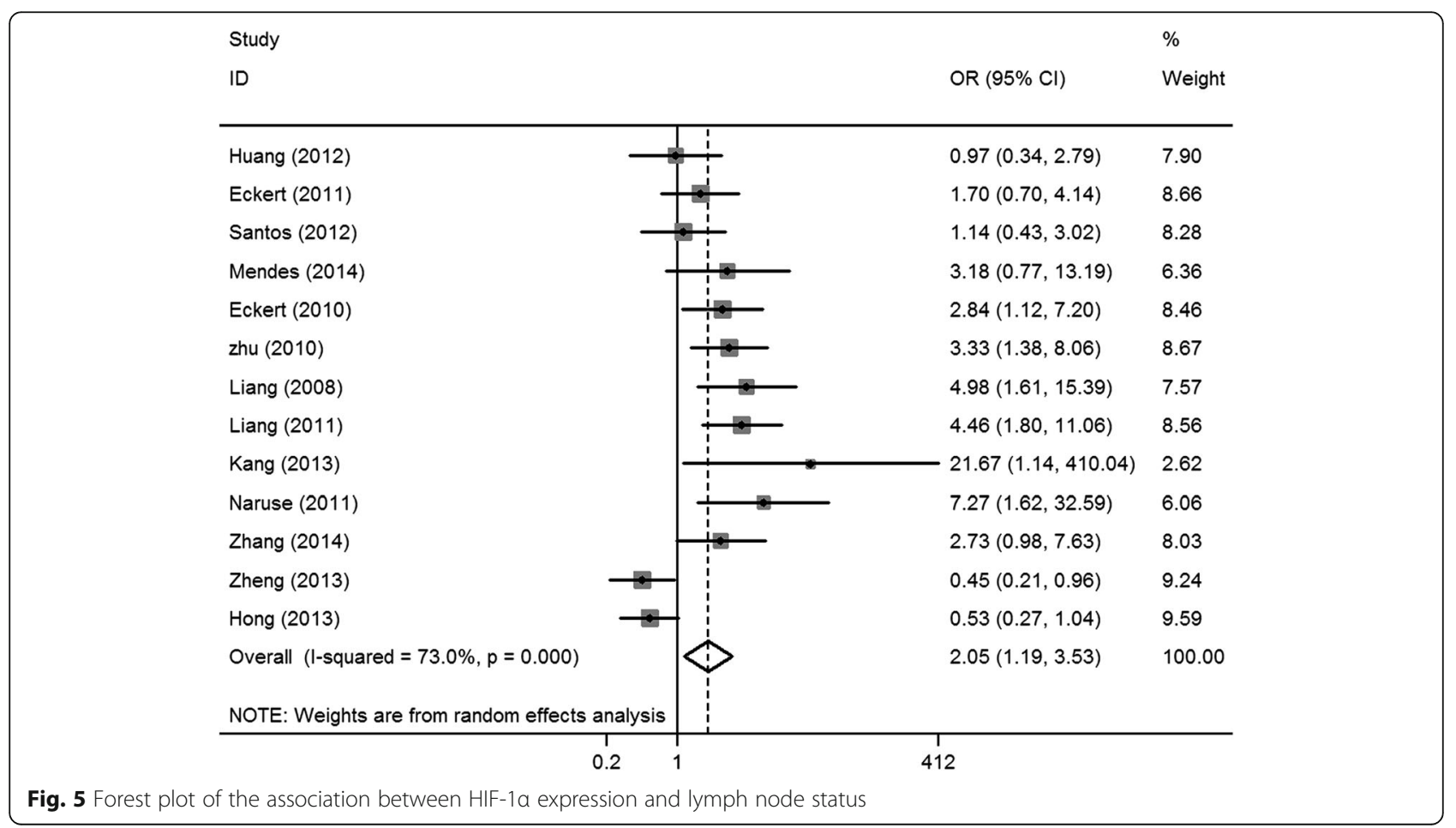




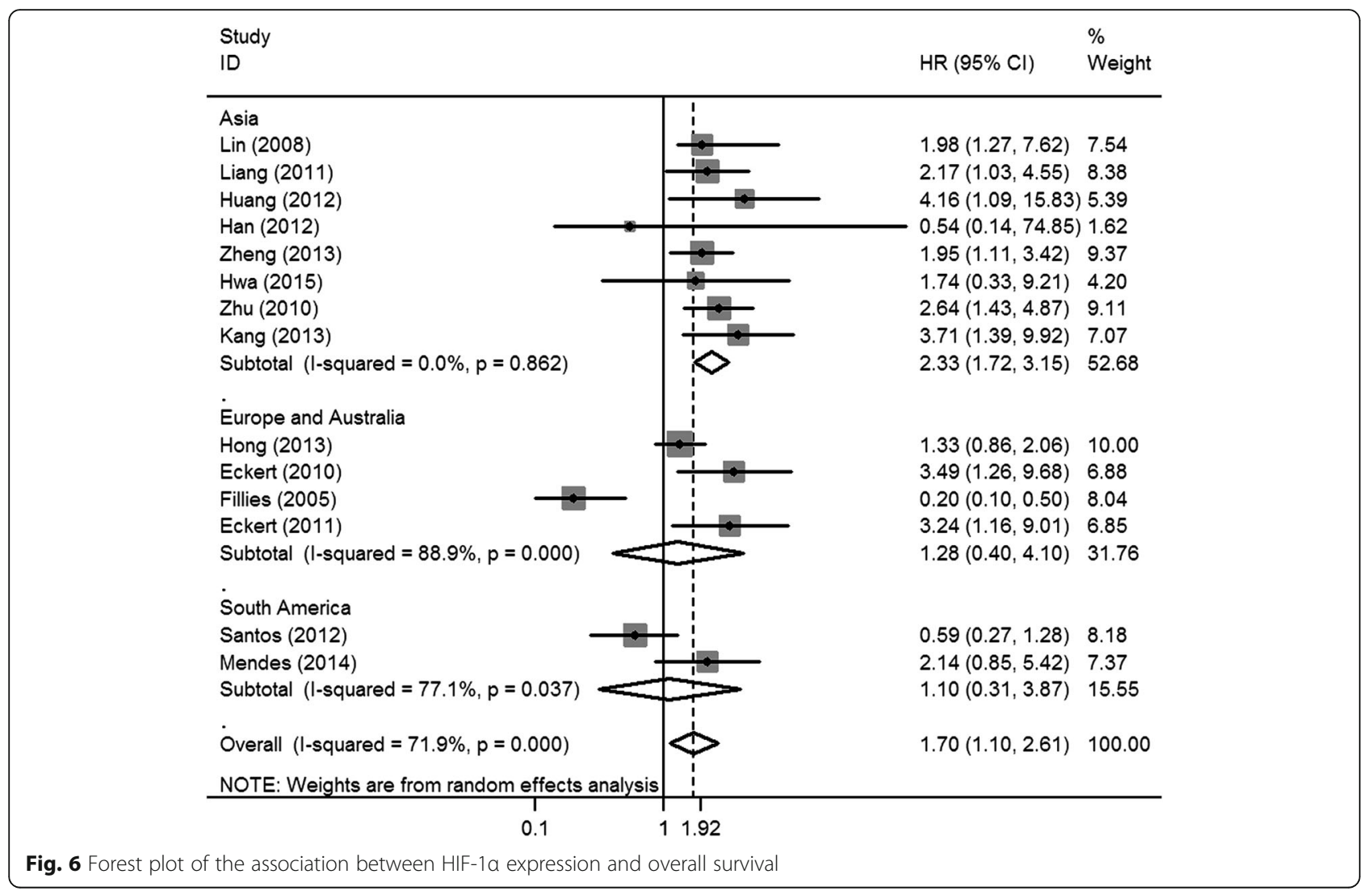

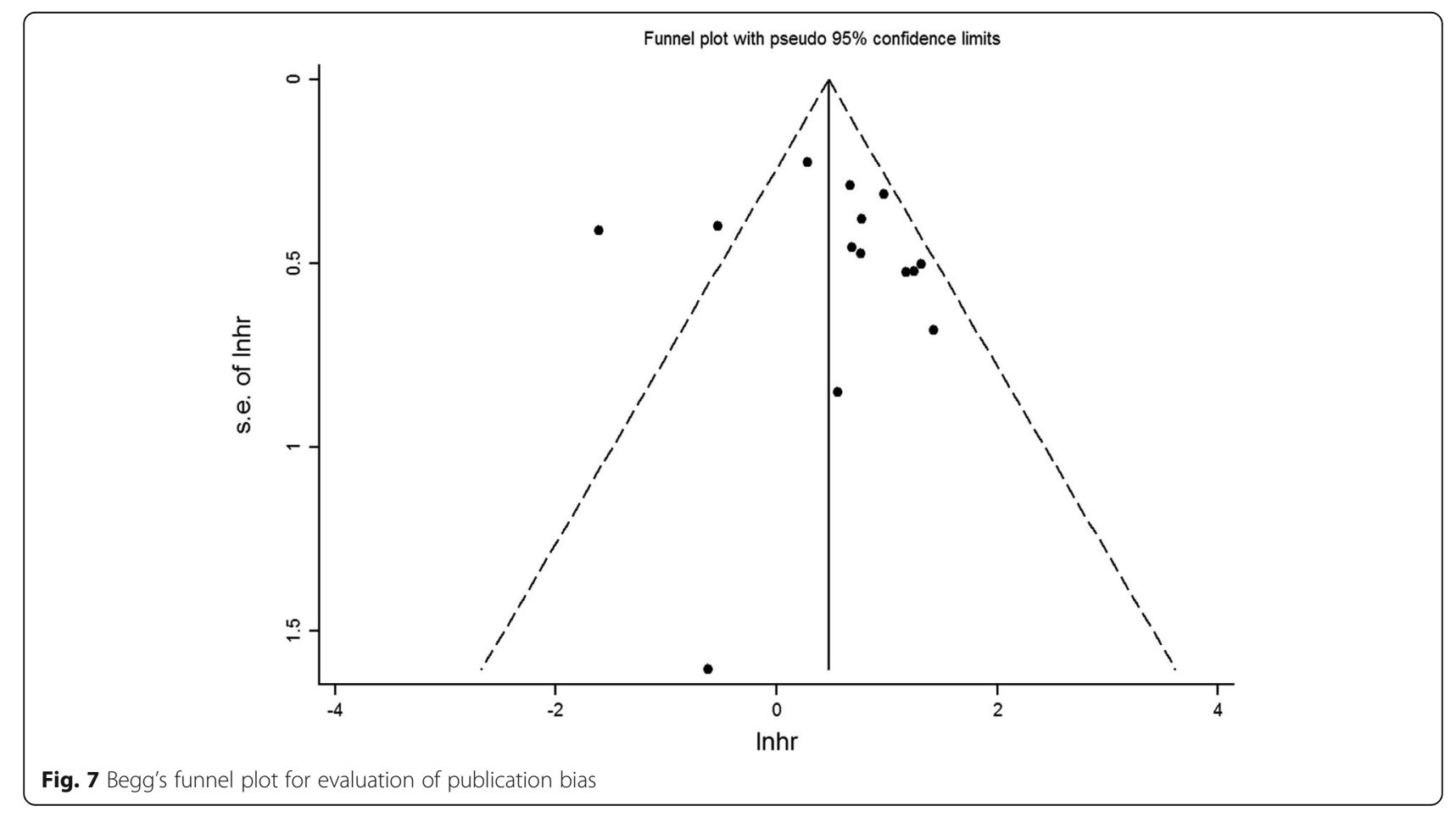


patients with low expression of HIF-1 $\alpha$ [27]. Therefore, we performed this meta-analysis to determine the clinical and prognostic significance of HIF- $1 \alpha$ overexpression in patients with OSCC.

The results of the present meta-analysis showed that increased expression of HIF- $1 \alpha$ protein, as detected with IHC, was significantly associated with larger tumor size (T3/T4), more advanced TNM stage (III/IV), and lymph node metastasis, but not with poor differentiation. This suggested an association of HIF-1 $\alpha$ overexpression with the biological behavior of OSCC. High expression of HIF$1 \alpha$ was defined based on a combination of the percentage of stained cells and the intensity of staining. Heterogeneity in tumor size, lymph node status, and histology were eliminated. We found this method as being particularly useful to define HIF-1 $\alpha$ expression in OSCC cells.

In the present meta-analysis, 14 eligible studies were included for the assessment of the association of HIF- $1 \alpha$ and overall survival. The results showed a significant association between HIF- $1 \alpha$ overexpression and poor overall survival. On subgroup analyses, a significant association between HIF- $1 \alpha$ overexpression and poor prognosis was found only in Asian population $(\mathrm{HR}=2.33,95 \% \mathrm{CI}=1.72-3.15)$, without significant heterogeneity in this respect. Therefore, this association is subject to considerable geographical variability. It is pertinent to mention here that geographical variations have been reported in the context of gastric cancer and head-neck cancer $[32,38]$. This phenomenon may be attributable to genetic differences between different ethnic groups [39]. Further studies are required to clarify this issue.

Some limitations of the present study need to be considered while interpreting our results. Firstly, only studies published in English were included in this analysis, which may have introduced an element of publication bias. Secondly, preoperative chemoradiation may have affected the prognosis of patients with OSCC. Data on preoperative treatment were available only for six studies, which may have contributed to the heterogeneity. Thirdly, the number of eligible studies was relatively small, which limits the statistical powder of our analysis. Finally, HRs were extracted from Kaplan-Meier curves in a few studies, which may not have been entirely accurate, thus contributing to the heterogeneity.

\section{Conclusions}

In conclusion, this meta-analysis provides a strong evidence of the association of HIF-1 $\alpha$ overexpression with both clinicopathological features and overall survival in patients with OSCC. Overexpression of HIF-1 $\alpha$ was significantly correlated with poorer prognosis in Asian population. HIF- $1 \alpha$ appears to be a valuable prognostic biomarker in patients with OSCC.

\section{Abbreviations}

Cl: Confidence interval; HIF-1a: Hypoxia inducible factor-1 alpha; HR: Hazard ratio; IHC: Immunohistochemistry; NOS: Newcastle-Ottawa quality assessment scale; OR: Odds ratio; OS: Overall survival; OSCC: Oral squamous cell carcinoma

\section{Acknowledgements}

We would like to acknowledge and thank the native English-speaking biologists who provided medical writing services on behalf of Medjaden Bioscience Limited.

\section{Funding}

This work was supported by the National Natural Science Foundation of China (NO. 81602144).

Availability of data and materials

All the data used in the study can be obtained from the original articles.

Authors' contributions

XXW and DSZ designed the study; JHZ and SYH collected the data; LLW and XY performed the statistical analysis; JHZ and SYH drafted the manuscript; and QJD revised and proofread the manuscript. All authors read and approved the final manuscript.

\section{Competing interests}

The authors declare that they have no competing interests.

Consent for publication

Not applicable.

Ethics approval and consent to participate

Not applicable.

\section{Publisher's Note}

Springer Nature remains neutral with regard to jurisdictional claims in published maps and institutional affiliations.

\section{Author details}

${ }^{1}$ Department of Oral and Maxillofacial Surgery, School of Stomatology, Shandong University, Jinan, Shandong 250012, China. ${ }^{2}$ Department of Oral and Maxillofacial Surgery, Shandong Provincial Hospital, Affiliated to Shandong University, Jinan, Shandong 250012, China. ${ }^{3}$ Department of Stomatology, Qingdao Municipal Hospital, Qingdao, Shandong 266071, China. ${ }^{4}$ Central laboratories, Qingdao Municipal Hospital, Qingdao, Shandong 266071, China.

Received: 30 January 2017 Accepted: 23 April 2017

Published online: 18 May 2017

\section{References}

1. Noguti J, De Moura CF, De Jesus GP, et al. Metastasis from oral cancer: an overview. Cancer Genomics Proteomics. 2012;9:329-35.

2. DE Lima PO, Jorge CC, Oliveira DT, et al. Hypoxic condition and prognosis in oral squamous cell carcinoma. Anticancer Res. 2014;34:605-12.

3. Zhong LP, Zhang CP, Ren GX, et al. Randomized phase III trial of induction chemotherapy with docetaxel, cisplatin, and fluorouracil followed by surgery versus up-front surgery in locally advanced resectable oral squamous cell carcinoma. J Clin Oncol. 2013;31:744-51.

4. Kim SY, Nam SY, Choi SH, et al. Prognostic value of lymph node density in node-positive patients with oral squamous cell carcinoma. Ann Surg Oncol. 2011;18:2310-7.

5. Lin PY, Yu CH, Wang JT, et al. Expression of hypoxia-inducible factor-1 alpha is significantly associated with the progression and prognosis of oral squamous cell carcinomas in Taiwan. J Oral Pathol Med. 2008;37:18-25.

6. Eckert AW, Lautner MH, Schutze A, et al. Coexpression of hypoxia-inducible factor-1a and glucose transporter-1 is associated with poor prognosis in oral squamous cell carcinoma patients. Histopathology. 2011;58:1136-47.

7. Semenza GL. Oxygen sensing, hypoxia-inducible factors, and disease pathophysiology. Annu Rev Pathol. 2014;9:47-71. 
8. Zheng $Y$, Ni Y, Huang $X$, et al. Overexpression of HIF-1a indicates a poor prognosis in tongue carcinoma and may be associated with tumour metastasis. Oncol Lett. 2013;5:1285-9.

9. Harris AL. Hypoxia-a key regulatory factor in tumour growth. Nat Rev Cancer. 2002;2:38-47.

10. Yao $H$, Wang $H$, Zhang $Z$, et al. Sulforaphane inhibited expression of hypoxia-inducible factor-1a in human tongue squamous cancer cells and prostate cancer cells. Int J Cancer. 2008;123:1255-61.

11. Isobe T, Aoyagi K, Koufuji K, et al. Clinicopathological significance of hypoxiainducible factor-1 alpha (HIF-1a) expression in gastric cancer. Int J Clin Oncol. 2013;18:293-304.

12. Qian J, Wenguang X, Zhiyong W, et al. Hypoxia inducible factor: a potential prognostic biomarker in oral squamous cell carcinoma. Tumour Biol. 2016; 37:10815-20.

13. Stang A. Critical evaluation of the Newcastle-Ottawa scale for the assessment of the quality of nonrandomized studies in meta-analyses. Eur J Epidemiol. 2010;25:603-5.

14. Parmar MK, Torri V, Stewart L. Extracting summary statistics to perform meta-analyses of the published literature for survival endpoints. Stat Med. 1998;17:2815-34.

15. Egger M, Smith GD, Schneider M, et al. Bias in meta-analysis detected by a simple, graphical test. BMJ. 1997;315:629-34.

16. Eckert AW, Schutze A, Lautner MH, et al. HIF-1a is a prognostic marker in oral squamous cell carcinomas. Int J Biol Markers. 2010;25:87-92.

17. Hong A, Zhang M, Veillard AS, et al. The prognostic significance of hypoxia inducing factor 1-a in oropharyngeal cancer in relation to human papillomavirus status. Oral Oncol. 2013;49:354-9.

18. Liang $X$, Zheng $M$, Jiang J, et al. Hypoxia-inducible factor-1 alpha, in association with TWIST2 and SNIP1, is a critical prognostic factor in patients with tongue squamous cell carcinoma. Oral Oncol. 2011;47:92-7.

19. Mendes SO, dos Santos M, Peterle GT, et al. HIF-1alpha expression profile in intratumoral and peritumoral inflammatory cells as a prognostic marker for squamous cell carcinoma of the oral cavity. PLoS One. 2014;9:e84923.

20. dos Santos M, Mercante AM, Louro ID, et al. HIF1-alpha expression predicts survival of patients with squamous cell carcinoma of the oral cavity. PLoS One. 2012;7:e45228.

21. Zhu GQ, Tang YL, Li L, et al. Hypoxia inducible factor $1 a$ and hypoxia inducible factor 2 a play distinct and functionally overlapping roles in oral squamous cell carcinoma. Clin Cancer Res. 2010;16:4732-41.

22. Naruse T, Kawasaki G, Yanamoto $\mathrm{S}$, et al. Immunohistochemical study of VEGF expression in oral squamous cell carcinomas: correlation with the mTOR-HIF-1a pathway. Anticancer Res. 2011:31:4429-37.

23. Zhang S, Zhou X, Wang B, et al. Loss of VHL expression contributes to epithelial-mesenchymal transition in oral squamous cell carcinoma. Oral Oncol. 2014;50:809-17.

24. Kang FW, Gao Y, Que L, et al. Hypoxia-inducible factor-1a overexpression indicates poor clinical outcomes in tongue squamous cell carcinoma. Exp Ther Med. 2013;5:112-8.

25. Liang $X$, Yang $D, H u$ J, et al. Hypoxia inducible factor-1alpha expression correlates with vascular endothelial growth factor-C expression and lymphangiogenesis/angiogenesis in oral squamous cell carcinoma. Anticancer Res. 2008;28:1659-66.

26. Vasconcelos MG, Vasconcelos RG, de Oliveira DH P, et al. Distribution of hypoxia-inducible factor-1a and glucose transporter-1 in human tongue cancers. J Oral Maxillofac Surg. 2015:73:1753-60.

27. Fillies $T$, Werkmeister $R$, van Diest PJ, et al. HIF1-alpha overexpression indicates a good prognosis in early stage squamous cell carcinomas of the oral floor. BMC Cancer. 2005;5:84.

28. Huang $C$, Sun Z, Sun Y, et al. Association of increased ligand cyclophilin A and receptor CD147 with hypoxia, angiogenesis, metastasis and prognosis of tongue squamous cell carcinoma. Histopathology. 2012;60:793-803.

29. Han MW, Lee HJ, Cho KJ, et al. Role of FDG-pet as a biological marker for predicting the hypoxic status of tongue cancer. Head Neck. 2012;34:1395-402.

30. Hwa JS, Kwon OJ, Park JJ, et al. The prognostic value of immunohistochemical markers for oral tongue squamous cell carcinoma. Eur Arch Otorhinolaryngol. 2015;272:2953-9.

31. Kappler M, Taubert H, Schubert J, et al. The real face of HIF-1 alpha in the tumor process. Cell Cycle. 2012;11:3932-6.

32. Gong L, Zhang W, Zhou J, et al. Prognostic value of HIFs expression in head and neck cancer: a systematic review. PLoS One. 2013;8:e75094.
33. Burri P, Djonov V, Aebersold DM, et al. Significant correlation of hypoxiainducible factor-1alpha with treatment outcome in cervical cancer treated with radical radiotherapy. Int J Radiat Oncol Biol Phys. 2003;56:494-501.

34. Schindl M, Schoppmann SF, Samonigg H, et al. Overexpression of hypoxiainducible factor 1alpha is associated with an unfavorable prognosis in lymph node-positive breast cancer. Clin Cancer Res. 2002;8:1831-7.

35. Birner $P$, Schindl M, Obermair A, et al. Expression of hypoxia-inducible factor 1alpha in epithelial ovarian tumors: its impact on prognosis and on response to chemotherapy. Clin Cancer Res. 2001;7:1661-8.

36. Chen WT, Huang CJ, Wu MT, et al. Hypoxia inducible factor-1alpha is associated with risk of aggressive behavior and tumor angiogenesis in gastrointestinal stromal tumor. Jpn J Clin Oncol. 2005;35:207-13.

37. Pérez-Sayáns M, Suárez-Peñaranda JM, Pilar GD, et al. Hypoxia-inducible factors in OSCC. Cancer Lett. 2011;313:1-8.

38. Zhu CL, Huang Q, Liu CH, et al. Prognostic value of HIF-1a expression in patients with gastric cancer. Mol Biol Rep. 2013;40:6055-62.

39. Quach H, Rotival M, Pothlichet J, et al. Genetic adaptation and neandertal admixture shaped the immune system of human populations. Cell. 2016; 167:643-56.

\section{Submit your next manuscript to BioMed Central and we will help you at every step:}

- We accept pre-submission inquiries

- Our selector tool helps you to find the most relevant journal

- We provide round the clock customer support

- Convenient online submission

- Thorough peer review

- Inclusion in PubMed and all major indexing services

- Maximum visibility for your research

Submit your manuscript at www.biomedcentral.com/submit
) Biomed Central 